\title{
Blockade of Stimulus Convergence in Amygdala Neurons Disrupts Taste Associative Learning
}

\author{
Koichi Hashikawa, ${ }^{1}$ Masamitsu Naka, ${ }^{1}$ Daisuke Nakayama, ${ }^{1}$ Nobuyoshi Matsumoto, ${ }^{1}$ Rachael Neve, ${ }^{2}$ \\ and Norio Matsuki ${ }^{1}$ \\ ${ }^{1}$ Laboratory of Chemical Pharmacology Graduate School of Pharmaceutical Sciences, The University of Tokyo, Tokyo 113-0033, Japan, and 2Picower \\ Institute, Massachusetts Institute of Technology, Cambridge, Massachusetts 02139
}

Humans and non-human animals learn associations of temporally contingent stimuli to better cope with the changing environment. In animal models of classical conditioning, a neutral conditioned stimulus (CS) predicts an aversive unconditioned stimulus (US). Several lines of indirect evidence indicate that this learning may rely on stimulus convergence in a subset of neurons, but this hypothesis has not been directly tested. In the current study, we tested this hypothesis using a pharmacogenetic approach, the cAMP response elementbinding protein (CREB)/Allatostatin Receptor system, to target a subset of amygdala neurons receiving convergent stimuli in mice during conditioned taste aversion. Virally infected basolateral amygdala neurons with higher CREB levels were predominantly active during CS presentation. Blocking stimulus convergence in infected neurons by silencing them during US disrupted taste associative memory. Moreover, silencing infected neurons only during CS also disrupted associative memory formation. These results provide support for the notion that convergent inputs of CS and US in a subpopulation of neurons are critical for associative memory formation.

\section{Introduction}

Through associative learning, humans and non-human animals learn that a sensory stimulus predicts the occurrence of an event. It has been proposed that associative memory formation critically relies on convergent inputs of the conditioned stimulus (CS) and the unconditioned stimulus (US) to a subpopulation of neurons (Blair et al., 2001; Johansen et al., 2010). Despite substantial progress in identifying brain regions involved in several associative learning tasks (Rogan et al., 1997; Yasoshima et al., 2000) and visualizing subpopulations of neurons responding to convergent stimuli (Barot et al., 2008; Chung et al., 2011), the requirement of stimulus convergence for associative learning has not been directly examined, because of the lack of a method for selectively targeting stimulus convergence. Selectively blocking stimulus convergence requires the selection of a subpopulation of neurons that are activated by the CS, and silencing them during US exposure. Since neurons active during CS are going to be active (stimulus convergence) or inactive during US, by silencing them

\footnotetext{
Received Nov. 26, 2012; revised Jan. 30, 2013; accepted Feb. 5, 2013.

Author contributions: K.H., D.N., N. Matsumoto, and N. Matsuki designed research; K.H., M.N., D.N., N. Matsumoto, and R.L.N. performed research; K.H., M.N., D.N., and N. Matsumoto analyzed data; K.H. wrote the paper.

This work was supported by grants from the Japan Society for the Promotion of Science (70126168) to N. Matsuki. We thank Dr. Alcino Silva for amplicon vectors of HSV-CREB and HSV-LacZ, Dr. Paul Worley for Arc CDNA, and Dr. Sheena Josselyn for GFP cDNA. We also thank Dr. Yu Zhou, Dr. Masanori Sakaguchi, Dr. Yasunori Hayashi, Aakane Sano, Dr. Takuya Takahashi for technical advice, Dr. Dayu Lin, and Yoshiko Yamasaki for helpful comments on the manuscript.

The authors declare no competing financial interests.

Correspondence should be addressed to Koichi Hashikawa, Laboratory of Chemical Pharmacology, Graduate School of Pharmaceutical Sciences, The University of Tokyo, 7-3-1 Hongo, Bunkyo-ku, Tokyo 113-0033, Japan. E-mail: lifeasadolphin@gmail.com.

DOI:10.1523/JNEUROSCI.5462-12.2013

Copyright $\odot 2013$ the authors $\quad 0270-6474 / 13 / 334958-06 \$ 15.00 / 0$
}

during US, stimulus convergence is blocked in the former neurons while the latter neurons keep inactivated during US.

We used a pharmacogenetic approach to achieve cell-specific manipulation of CREB (cAMP response element-binding protein) levels, and reversible inactivation of targeted cells to selectively block stimulus convergence (Zhou et al., 2009). Recent studies have suggested that amygdala neurons with relatively high CREB levels are preferentially recruited in associative memory traces, such as fear and taste aversive memories (Han et al., 2007, 2009; Zhou et al., 2009). Neurons with higher CREB levels are predominantly active during fear conditioning and fear memory retrieval (Han et al., 2007). Manipulation of CREB levels in a subset of neurons may also allow investigators to specifically target the neuronal population that is activated by CS.

Conditioned taste aversion (CTA) is a simple form of associative learning during which a novel taste (CS) is paired with visceral malaise (US) (Bermúdez-Rattoni, 2004). In associative learning tasks such as fear conditioning, the CS and US are typically separated for no more than several seconds, or at most a couple of minutes. In contrast, CTA can be acquired with delays of several minutes or even hours between CS and US presentation. This longer interval allows for the silencing of targeted neurons during CS or US using a pharmacogenetic approach. We focused on the basolateral nucleus of the amygdala (BLA), which is critically involved in CTA acquisition (Yasoshima et al., 2000; Josselyn et al., 2004), and where a subpopulation of neurons receiving convergent inputs of CS and US has previously been visualized (Barot et al., 2008).

\section{Materials and Methods}

Subjects. Adult male C57BL/6J mice were group-housed on a $12 \mathrm{~h}$ light/ dark cycle. Food and water were available ad libitum before the behav- 
A

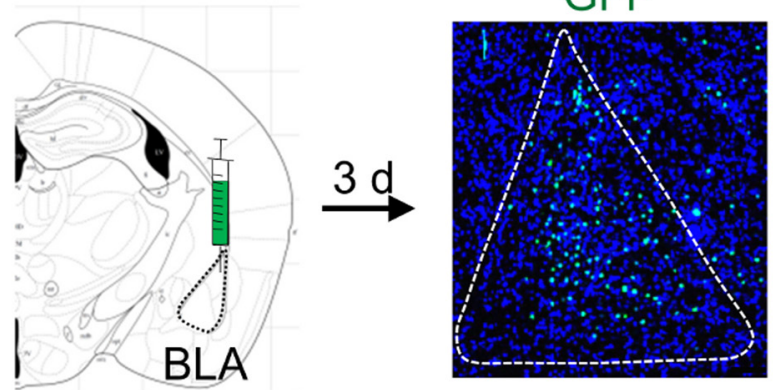

B

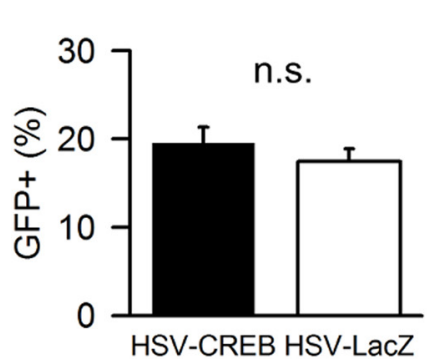

C

ACSF

$20 \mathrm{nM}$ Allatostatin

GFP (+)
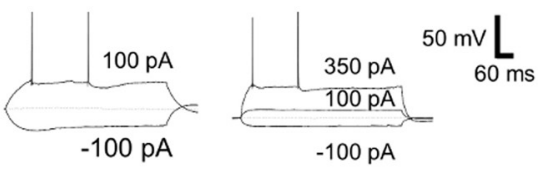

GFP (-)
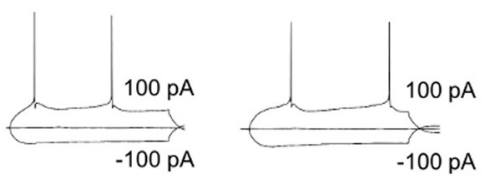

Figure 1. Selective viral expression in the BLA with HSV-CREB or HSV-LacZ. A, Left, Outline of the BLA. Right, A representative image of localized GFP (green) expression in the BLA $3 \mathrm{~d}$ following viral injection. Blue, Nuclei. Scale bar, $80 \mu \mathrm{m}$. B, Approximately $20 \%$ of BLA neurons expressed GFP in the infected region following HSV-CREB or HSV-LaCZ infusion ( $n=4$ mice/group). $C$, Representative traces showing that allatostatin selectively and quickly $(\sim 5 \mathrm{~min})$ inactivated an infected pyramidal neuron in the BLA (top). Error bars represent SEM.

ioral experiments. Mice were treated in accordance with guidelines approved by The University of Tokyo.

HSV vectors. HSV-CREB-AlstR (HSV-CREB) and HSV-LacZ-AlstR (HSV-LacZ) were used (Zhou et al., 2009). The HSV amplicons were kindly provided by Dr. Alcino Silva (The University of California, Los Angeles). For visualization of transgene expression, eGFP was fused to the end of the CREB and LacZ cDNA. Creb 1 and LacZ were expressed using an IE4/5 promoter, and AlstR was expressed with a CMV promoter. The amplicons were packaged according to a published method (Lim and Neve, 2001).

Surgery and virus infusion. Anesthesia was induced with Nembutal (5 $\mathrm{mg} / \mathrm{kg}$ body weight, injected intraperitoneally). The scalp was opened, and holes were drilled in the skull bilaterally above the BLA (AP, -1.4; $\mathrm{LM}, \pm 3.5, \mathrm{DV},-4.9 \mathrm{~mm}$ from bregma) according to a mouse brain atlas (Paxinos and Franklin, 2001). For behavioral experiments, guide cannulae (Plastics One, 26 gauge) were implanted just dorsal to the BLA and fixed on the skull with dental cement. Virus infusion was delayed until $10 \mathrm{~d}$ after surgery to ensure physical recovery. A virus solution $(1.5 \mu \mathrm{l}$, bilateral) was delivered to the BLA at a flow rate of $0.075 \mu \mathrm{l} \mathrm{min}{ }^{-1}$ through inner injection cannulae (Plastics One, 33 gauge) using an infusion pump (Muromachi). The injection cannula was left in place for an additional $10 \mathrm{~min}$ to ensure diffusion of the virus. For electrophysiological or fluorescence in situ hybridization (FISH) studies, virus solution (1.5 $\mu \mathrm{l}$, bilateral) was delivered to the BLA at a flow rate of $0.075 \mu \mathrm{l}$ min $^{-1}$ through glass micropipettes (World Precision Instruments) immediately after the holes were drilled. The micropipette was left in place for an additional $10 \mathrm{~min}$. Electrophysiological, FISH, and behavioral experiments were performed $3 \mathrm{~d}$ following virus infusion.

Allatostatin administration. The peptide allatostatin (Phoenix Pharmaceuticals) was dissolved in double-distilled water to make a $2.5 \mathrm{~mm}$ stock solution. Saline was added to dilute it to the final concentration for each experiment. For behavioral studies, allatostatin solution (100 $\mu \mathrm{M}, 0.5 \mu \mathrm{l})$ or the vehicle saline $(0.5 \mu \mathrm{l})$ was infused bilaterally to the BLA of freely moving mice at a flow rate of $0.25 \mu \mathrm{lmin}^{-1}$ through inner injection cannulae. The cannulae were left in place for an additional $2 \mathrm{~min}$.

Arc and GFP double FISH. Five minutes after the onset of CS or US exposure, brains were extracted, frozen, and stored at $-80^{\circ} \mathrm{C}$. Brains were cut into $20 \mu \mathrm{m}$ coronal slices using a cryostat and mounted onto slides. Digoxigenin-labeled Arc riboprobes and fluorescein-labeled GFP riboprobes were generated from modified cDNA plasmids. FISH for Arc and GFP mRNA followed previous reports (Han et al., 2007; Hashikawa et al., 2011). Arc and GFP signals were visualized using the Cyanine 3 and Cyanine 5 TSA system (PerkinElmer). Nuclei were counterstained with Hoechst (Invitrogen). Three to four sections including the BLA were analyzed per mouse. Images were acquired using a Leica SP5 confocal microscope with a $40 \times$ objective lens. $Z$-series stacks $(1-\mu \mathrm{m}$-thick optical sections) were constructed and analyzed using the MetaMorph 6.0 program. Analysis was performed by three experimenters blind to group membership. Only neurons with fully intact nuclei were scored. For neurons to be considered Arc positive for nuclear staining, one or two robust foci within their nuclei were required. Perinuclear signals were required for neurons to be considered cytoplasmic Arc positive.

CTA. Mice were deprived of water for $24 \mathrm{~h}$, then adapted to a water-restriction schedule for $4 \mathrm{~d}$ with two daily drinking sessions at 9:00 A.M. (60 min initially, gradually reduced to 5 $\mathrm{min}$ ) and at 5:00 P.M. (for $60 \mathrm{~min}$ ) from two tubes filled with water. HSV was bilaterally infused into the BLA on the second day of the water restriction. Conditioning took place $3 \mathrm{~d}$ after the viral injection.

On the conditioning day, a tube filled with $0.2 \%$ saccharin sodium salt (w/v, CS) was presented for $5 \mathrm{~min}$ (short-interval conditioning) or 30 min (long-interval conditioning). Mice were treated with an intraperitoneal injection of $0.06 \mathrm{M} \mathrm{LiCl}$ ( $2 \%$ of body weight) $30 \mathrm{~min}$ (short interval) or $2.5 \mathrm{~h}$ (long interval) after the CS.

Testing for aversion to saccharin took place $24 \mathrm{~h}$ after the conditioning. Two tubes (one filled with water and the other filled with saccharin) were presented for $10 \mathrm{~min}$. The intake of each fluid was measured. The aversion index was defined as (milliliters of water consumption)/(milliliters of water consumption + milliliters of saccharin consumption) and used as an index for learned aversion for saccharin.

After the behavioral experiments, mice were killed by transcardial perfusion with PBS, followed by $4 \%$ paraformaldehyde (w/v). Following perfusion, brains were left in $4 \%$ paraformaldehyde for $1 \mathrm{~d}$ and then moved to a $30 \%$ sucrose solution (w/v) in PBS for $2-3 \mathrm{~d}$. Brains were frozen and sliced coronally $(40 \mu \mathrm{m})$ with a cryostat. To identify cannula tip locations, relevant sections were mounted on slides and stained with crystal violet. Only those mice with bilateral placements in the BLA were included in the analysis.

Electrophysiology. Acute brain slices were prepared from BLA neurons of adult mice $3 \mathrm{~d}$ after viral infusion as previously described (Miura et al., 2012). Slices were perfused with artificial CSF containing the following (in mM): 127 $\mathrm{NaCl}, 1.6 \mathrm{KCl}, 1.24 \mathrm{KH}_{2} \mathrm{PO}_{4}, 1.3 \mathrm{mM} \mathrm{MgSO}_{4}, 2.4 \mathrm{CaCl}_{2}, 26 \mathrm{NaHCO}_{3}$, and 10 glucose at $31^{\circ} \mathrm{C}$. Cells were visualized using infrared or epifluorescent illumination, and whole-cell current-clamp recordings were made from neurons in BLA. Patch electrodes (3-6 M $\Omega$ ) contained (in mM): $120 \mathrm{~K}$-gluconate, 5 $\mathrm{KCl}, 10$ HEPES, $1 \mathrm{MgCl}_{2}$, 10 phosphocreatine- $\mathrm{Na}_{2}, 2 \mathrm{MgATP}, 0.2 \mathrm{Na}_{2} \mathrm{GTP}$, 0.2 EGTA, and 0.04 Alexa Fluor 568, pH 7.2-7.3, 280-295 mOsm. Access resistance was monitored throughout the experiments. Only putative pyramidal neurons in BLA defined as healthy (resting membrane potential more negative than $-55 \mathrm{mV}$ ) were included in the analysis. Allatostatin $(20 \mathrm{~nm})$ was applied by adding it to the superfusate. Physiological measures before, after 5 min of perfusion with allatostatin, and 15-20 min after washout were compared. 
Data analysis. All values were reported as means \pm SEM. ANOVA was used for data analysis with post hoc comparisons performed using Student's $t$ test to determine the significance of differences between two groups. Comparisons within an individual mouse were performed using paired $t$ test.

The probability of $\mathrm{Arc}^{+}$neurons in $\mathrm{GFP}^{+}$ or $\mathrm{GFP}^{-}$cells was calculated as follows: Arc $(+)$ in GFP $(+)(\%)=$ (the number of cells with Arc and GFP signals/total number of GFP $(+)$ cells $) \times 100$. Arc $(+)$ in GFP $(-)(\%)=$ (the number of cells with Arc and no GFP signals/total number of GFP $(-)$ cells $) \times 100$.

\section{Results}

To selectively target and silence cells that are active during CS presentation, the BLA was injected with CREB-AlstR HSV (HSV-CREB), which coexpresses CREB tagged with green fluorescent protein (GFP) and the Drosophila allatostatin G-protein-coupled receptor (AlstR). For the control virus (HSV-LacZ), CREB was replaced with $\beta$-galactosidase (LacZ) (Zhou et al., 2009). Allatostatin administration selectively and reversibly silences neurons expressing AlstR through the activation of endogenous mammalian G-protein-coupled inwardly rectifying $\mathrm{K}^{+}$channels (Tan et al., 2006). Indeed, we confirmed that administration of allatostatin selectively silenced BLA neurons infected with the viruses by performing whole-cell patch-clamp recording (Fig. $1 C)$. Detection of GFP mRNA by FISH revealed that $\sim 20 \%$ of neurons in the injected region in the BLA were $\mathrm{GFP}^{+}$with both HSVs, and these cells were preferentially localized in the BLA. No significant difference was found between the infection rates for the HSV-CREB and HSVLacZ viruses $(19 \pm 2 \%$ versus $17 \pm 1 \%$, $n=4$ mice per group, Student's $t$ test, $t_{(6)}$ $=0.915, p=0.395$; Fig. $1 A, B)$.

We investigated whether virally infected cells overexpressing CREB are preferentially active during CS. To visualize cellular activation, we used the activitydependent gene Arc (activity-regulated cytoskeleton-associated protein; also termed Arg3.1) (Guzowski et al., 1999; Barot et al., 2008). Arc mRNA signal first presents in the nucleus (5-10 $\mathrm{min})$ and then translocates to the cytoplasm over time $(\sim 30 \mathrm{~min})$. We injected HSV-CREB or HSV-LacZ into the BLA $3 \mathrm{~d}$ before saccharin presentation. Five minutes after saccharin presentation, brains were harvested for double FISH to detect intranuclear Arc and GFP mRNA in the BLA. Overall, the percentage of Arc + cells was higher following saccharin presentation compared with home cage controls in mice injected with HSV-CREB (Student's $t$ test, $t_{(6)}=5.533, p=0.0015$; Fig. $2 B$ ). Furthermore, the probability of detecting Arc + nuclei in the saccharin group was higher in neurons with HSV-CREB than in their noninfected neighbors (paired $t$ test, $t_{(3)}=16.684, p=0.00047$; Fig. $2 C$ ). In contrast, neurons with HSV-LacZ were no more likely to be Arc+ Error bars represent SEM.
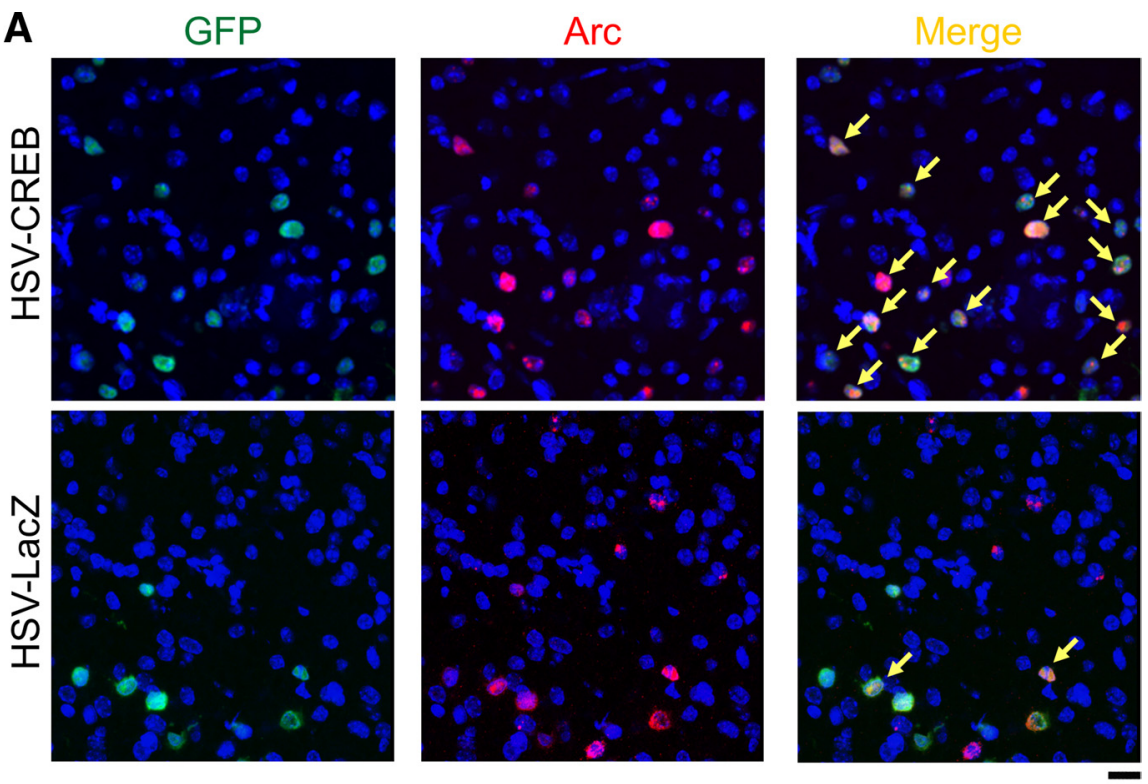

C

HSV-CREB

HSV-LacZ
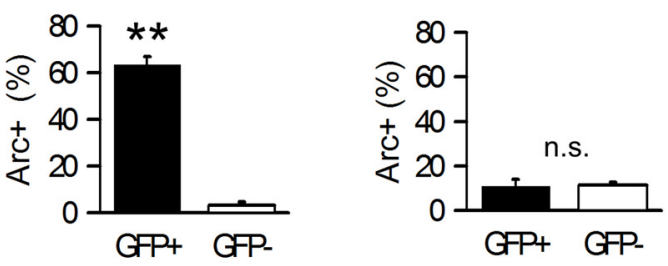

E

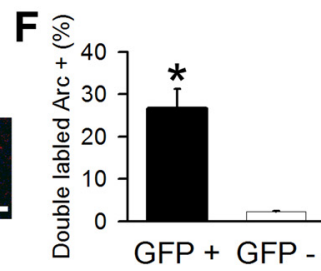

Figure 2. BLA neurons with high CREB levels are preferentially active during CS presentation. $\boldsymbol{A}$, Representative confocal images of $\operatorname{Arc}$ (red) and GFP (green) expression in the BLA neurons. Mice were injected with HSV-CREB (top) or HSV-LacZ (bottom) $3 \mathrm{~d}$ before $C S$ presentation. They were killed 5 min after the onset of $C S$ presentation. Blue, Nuclei; yellow arrows, colocalized neurons

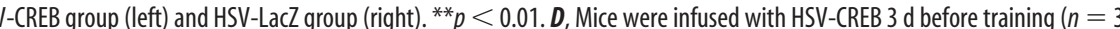
. They were presented with CS for $5 \mathrm{~min}$ (30 min before they were killed) and US ( 5 min before they were killed). $E$, (red). Blue, Nuclei. Scale bar, $10 \mu \mathrm{m}$. $\boldsymbol{F}$, The proportion of double-labeled Arc $^{+}$neurons in GFP ${ }^{+}$or GFP ${ }^{-}$neurons. ${ }^{*} p<0.05$.

than were their noninfected neighbors (paired $t$ test, $t_{(3)}=-0.158$, $p=0.88$; Fig. $2 C$ ). These results indicate that amygdala neurons with increased CREB function were preferentially activated by saccharin presentation.

In addition, infected neurons with HSV-CREB were preferentially activated by convergent stimuli (Fig. 2D-F). HSVCREB was injected in the BLA $3 \mathrm{~d}$ before CS and US presentation. Double FISH for detecting Arc and GFP mRNA in the BLA revealed that the percentage of double-labeled Arcpositive neurons with intranuclear and cytoplasmic signals was significantly higher in GFP $(+)$ neurons than in GFP $(-)$ neurons after CS and US presentation (paired $t$ test, $t_{(2)}=$ 5.336, $p=0.033$; Fig. $2 F)$. 
A
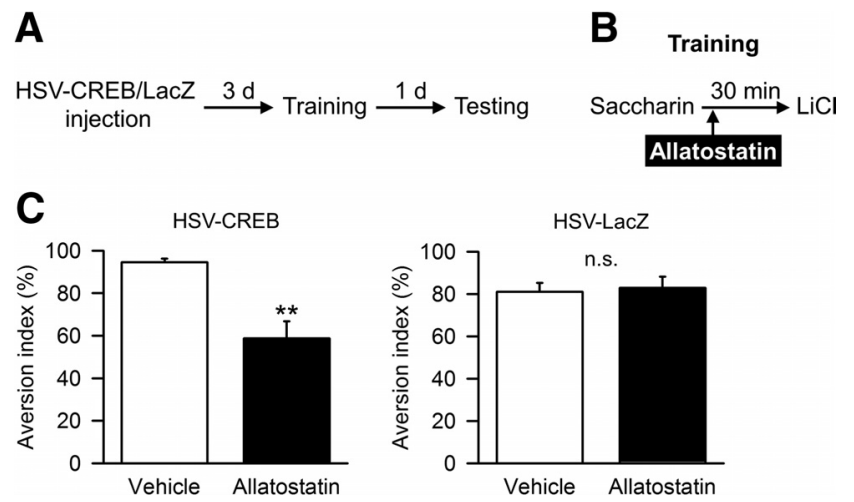

Figure 3. Silencing BLA neurons activated by $C S$ during US disrupts taste associative learning. $\boldsymbol{A}$, Schematic of the experimental design. Mice were injected with HSV-CREB ( $n=13$ mice/group) or HSV-LacZ ( $n=10-11$ mice/group) $3 \mathrm{~d}$ before training. $\boldsymbol{B}$, Schematic of the training protocol. C, Allatostatin infusion disrupted conditioned taste aversion memory only in mice injected with HSV-CREB. ${ }^{* *} p<0.01$. Error bars represent SEM.

To test whether selective silencing of neurons activated by CS during US presentation disrupts associative learning, we examined whether inactivation of amygdala neurons infected with HSV-CREB during US presentation attenuates taste associative learning. We bilaterally injected HSV-CREB into the BLA $3 \mathrm{~d}$ before CTA. On the conditioning day, mice were presented with the CS for $5 \mathrm{~min}$. To inactivate infected neurons during US presentation, mice received an allatostatin infusion in the BLA (100 $\mu \mathrm{M}, 0.5 \mu \mathrm{l}$ ) immediately after the termination of CS presentation. Thirty minutes after the allatostatin infusion, mice were injected with lithium chloride ( $\mathrm{LiCl}$, US). Mice treated with allatostatin exhibited lower aversion index compared with mice treated with vehicle saline ( $n=13$ mice per group, Student's $t$ test, $t_{(24)}=$ 4.420, $p=0.00069$; Fig. 3C).

There is a possibility that random inactivation of $\sim 20 \%$ of BLA neurons during US presentation might also disrupt CTA. We examined whether selective silencing of amygdala neurons infected with HSV-LacZ during US presentation could disrupt taste associative learning. We found that aversion index in allatostatin-treated mice were comparable to those in vehicle mice ( $n=10-11$ mice per group, Student's $t$ test, $t_{(19)}=0.268$, $p=0.79$; Fig. $3 C$ ). These results are consistent with the hypothesis that selective silencing of BLA neurons activated by CS during US presentation disrupts taste associative learning.

Next, we examined how long allatostatin administration affected CTA memory retrieval. We injected HSV-CREB in the BLA 3 d before CTA training. One day after the conditioning, we administered allatostatin in the BLA $30 \mathrm{~min}$ or $3 \mathrm{~h}$ before the test. Consistent with previous reports (Zhou et al., 2009), allatostatin infusion $30 \mathrm{~min}$ before the test impaired CTA memory retrieval $\left(n=8-10\right.$ mice per group, Student's $t$ test, $t_{(16)}=2.162, p=$ 0.046; Fig. 4B), while allatostatin infusion $3 \mathrm{~h}$ before the test had no effect on it ( $n=8-9$ mice per group, Student's $t$ test, $t_{(15)}=$ $-0.450, p=0.66$; Fig. $4 C$ ), indicating that the effect of allatostatin on CTA memory lasted for at least $30 \mathrm{~min}$, but no longer than $3 \mathrm{~h}$.

If stimulus convergence in a subset of neurons is critical for associative learning, inactivation of those neurons only during CS should also disrupt memory formation. To silence virally infected cells during CS without having any effect during US, we performed long-interval CTA in which CS and US were separated for $2.5 \mathrm{~h}$ (Fig. 4). Because allatostatin was administered $3 \mathrm{~h}$ before US presentation, allatostatin should not have had an effect during US
A

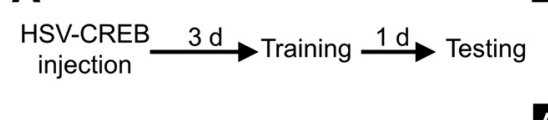

B Testing

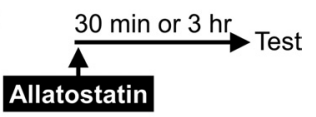

C
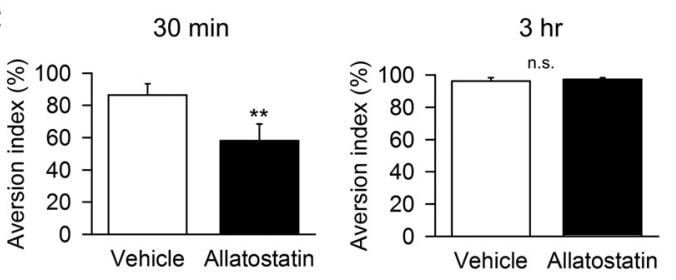

D

Training

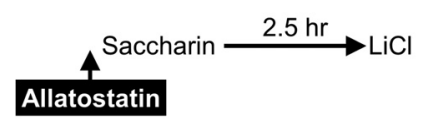

E Training
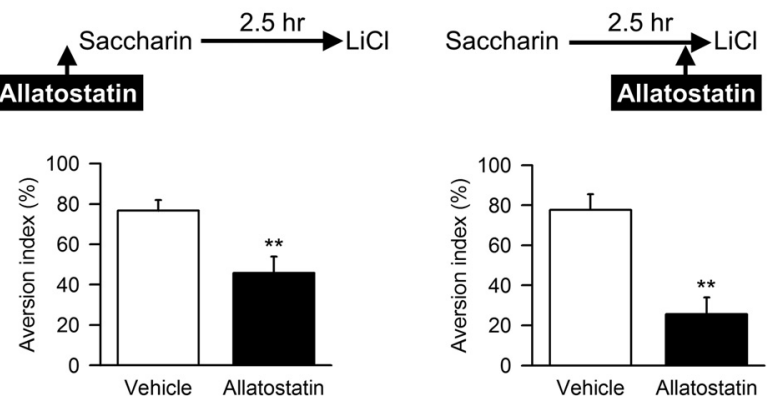

Figure 4. Silencing BLA neurons with high CREB level during CS disrupts taste associative learning. $A$, Schematic of the experimental design. Mice were infused with HSV-CREB $3 \mathrm{~d}$ before training. $\boldsymbol{B}$, Schematic of the testing protocol. Mice were infused with allatostatin $30 \mathrm{~min}(n=$ $8-10$ mice/group) or $3 \mathrm{~h}$ ( $n=8-9$ mice mice/group) before the test. C, (TA memory retrieval was impaired only when allatostatin was infused 30 min before the test. ${ }^{*} p<0.05$. D, E, Mice received the US for $2.5 \mathrm{~h}$ after the onset of $C S$ on the conditioning day. $D$, Top, Mice were infused with allatostatin $30 \mathrm{~min}$ before $C S$ presentation on the conditioning day. Bottom, Allatostatin infusion disrupted CTA memory ( $n=10-11$ mice/group). ${ }^{* *} p<0.01$. $\boldsymbol{E}$, Top, Mice were infused with allatostatin $30 \mathrm{~min}$ before US presentation on the conditioning day. Bottom, Allatostatin infusion disrupted CTA memory ( $n=10$ mice/group). ${ }^{* *} p<0.01$. Error bars represent SEM.

(Fig. 4C). We injected HSV-CREB in the BLA $3 \mathrm{~d}$ before CTA training. On the conditioning day, mice were injected with allatostatin into BLA $30 \mathrm{~min}$ before the CS. Mice treated with allatostatin exhibited lower aversion index scores than mice injected with the vehicle $\left(n=10-11\right.$ mice per group, $t_{(19)}=3.181, p=$ 0.0049; Fig. 4D). Moreover, consistent with the results of shortinterval CTA in which CS and US were separated for $30 \mathrm{~min}, \mathrm{CTA}$ memory formation was disrupted when allatostatin was administered $30 \mathrm{~min}$ before US presentation to inactivate infected cells during US $\left(n=10\right.$ mice per group, $t_{(18)}=4.564$, $p=0.00024$; Fig. $4 E)$.

\section{Discussion}

The current results suggest that activation of a subset of amygdala neurons by coincident inputs of CS and US is crucial for taste associative memory. We found that virally infected BLA neurons with higher CREB levels were predominantly activated by CS. Silencing of these infected neurons during US exposure disrupted CTA. Importantly, silencing a comparable number of basolateral amygdala neurons infected with control HSV expressing LacZ as replacement of CREB during US had no effect on associative memory formation, indicating that random silencing of $\sim 20 \%$ of neurons in BLA during US does not attenuate CTA. Moreover, silencing of infected cells with high CREB levels during CS also disrupted CTA. The results revealed that blocking stimulus con- 
vergence in infected neurons by silencing them during either CS or US exposure attenuated taste associative memory formation.

An increasing body of evidence suggests that the basolateral amygdala is a critical site of association for CTA. Activation of NMDA receptors in BLA is crucial for habituation to novel tastes (Figueroa-Guzmán and Reilly, 2008). Elevated extracellular glutamate release has been found in the BLA after US presentation (Miranda et al., 2002). Stimulus convergence in a subpopulation of neurons has previously been visualized in mice while acquiring an association between CS and US (Barot et al., 2008; Chung et al., 2011). The requirements of molecular signaling pathways for synaptic plasticity and its consolidation, such as cAMP, PKA and de novo protein synthesis, have been reported in the amygdala (Koh et al., 2002; Josselyn et al., 2004). Moreover, a subset of BLA neurons has been found to show plastic changes in responsiveness to CS after CTA training (Grossman et al., 2008; Kim et al., 2010). Although these studies provide indirect evidence that CTA is dependent on stimulus convergence in the BLA, several studies have reported conflicting findings regarding its role in CTA (Bermúdez-Rattoni, 2004; Reilly and Bornovalova, 2005). To test the hypothesis more directly, it is necessary to selectively silence a subpopulation of neurons activated by the CS during US exposure only. The present study indicated that blockade of stimulus convergence in the BLA disrupted CTA memory. These findings support the notion that the formation of associations in the BLA is crucial for CTA memory.

We genetically manipulated CREB to select BLA neurons activated by the CS. We found that BLA neurons with higher CREB levels were more likely to be activated by CS exposure than noninfected neighboring cells. Although the mechanisms underlying this preferential recruitment remain unclear, recent studies have implicated two possible mechanisms. First, neurons with higher CREB levels may exhibit greater excitability, since the overall excitability of neurons can be modulated by CREB (Benito and Barco, 2010). Genetic overexpression or inhibition of CREB caused increased or decreased excitability in amygdala neurons, but also in the locus ceruleus, nucleus accumbens, and hippocampal neurons. Second, an intrinsic inhibitory network in the BLA may explain the current findings. Previous studies have suggested that a strong inhibitory network exists in the dorsoventral, lateral medial, and rostral caudal directions, operating through local interneurons (Samson and Paré, 2006). More excitable neurons with higher CREB levels are predominantly activated by CS, but may simultaneously inhibit noninfected neighboring neurons through local interneurons. Interestingly, this preferential recruitment of neurons with higher CREB is not unique to CTA, but may be a general phenomenon in amygdala-dependent associative learning. The amygdala has long been proposed as the site of CS-US association in fear conditioning (Blair et al., 2001). A genetically manipulated amygdala neurons with higher CREB levels has been reported to be preferentially recruited in fear memory trace (Han et al., 2009).

We found that silencing of cells infected with HSV-CREB only during CS disrupted CTA (Fig. 4D). This result, however, may not be simply accounted by the blockade of stimulus convergence in the amygdala. While neurons infected with HSV-CREB were silenced during CS by allatostatin application, the neuronal activities of noninfected neighboring neurons were unaffected. Thus, the noninfected neurons could have been recruited to CTA memory. A possible explanation could be that interference between infected neurons and noninfected neurons during US might have impaired CTA. Since allatostatin was no longer effective during US (Fig. 4C), infected neurons might be competitively activated and interfere with the activation of noninfected cells by US presentation. In addition, a shift in amygdala network might have been induced during CS-US interval by the recovery of the infected cells after their silence. This shift in amygdala network may have further effects on neural activation during US. Further studies are required to clarify this issue.

In the present study, we took advantage of the relatively long interval between CS and US in the CTA paradigm (from tens of minutes to hours), applying CREB/Allatostatin system. We found that the effect of allatostatin lasted for at least $30 \mathrm{~min}$ and no longer than $3 \mathrm{~h}$. Previous reports have also demonstrated that allatostatin selectively and reversibly silenced neurons expressing AlstR for between several minutes and a few hours in vivo (Tan et al., 2006; Zhou et al., 2009). The quickness and reversibility of the effect of allatostatin allowed us to silence a specific population of neurons during CS or US periods. Although we used these two complementary approaches to block stimulus convergence, the exact timing or duration of CS and US convergence remains unclear, because extracellular glutamate is upregulated for $1-2 \mathrm{~h}$ in the BLA after intraperitoneal injection of LiCl (Miranda et al., 2002). It will be important for future studies to specifically manipulate cellular activation during CS or US using approaches with better temporal resolution, such as optogenetic manipulation (Sakaguchi and Hayashi, 2012).

\section{References}

Barot SK, Kyono Y, Clark EW, Bernstein IL (2008) Visualizing stimulus convergence in amygdala neurons during associative learning. Proc Natl Acad Sci U S A 105:20959-20963. CrossRef Medline

Benito E, Barco A (2010) CREB's control of intrinsic and synaptic plasticity: implications for CREB-dependent memory models. Trends Neurosci 33: 230-240. CrossRef Medline

Bermúdez-Rattoni F (2004) Molecular mechanisms of taste-recognition memory. Nat Rev Neurosci 5:209-217. CrossRef Medline

Blair HT, Schafe GE, Bauer EP, Rodrigues SM, LeDoux JE (2001) Synaptic plasticity in the lateral amygdala: a cellular hypothesis of fear conditioning. Learn Mem 8:229-242. CrossRef Medline

Chung A, Barot SK, Kim JJ, Bernstein IL (2011) Biologically predisposed learning and selective associations in amygdalar neurons. Learn Mem 18:371-374. CrossRef Medline

Figueroa-Guzmán Y, Reilly S (2008) NMDA receptors in the basolateral amygdala and gustatory neophobia. Brain Res 1210:200-203. CrossRef Medline

Grossman SE, Fontanini A, Wieskopf JS, Katz DB (2008) Learning-related plasticity of temporal coding in simultaneously recorded amygdalacortical ensembles. J Neurosci 28:2864-2873. CrossRef Medline

Guzowski JF, McNaughton BL, Barnes CA, Worley PF (1999) Environment-specific expression of the immediate-early gene Arc in hippocampal neuronal ensembles. Nat Neurosci 2:1120-1124. CrossRef Medline

Han JH, Kushner SA, Yiu AP, Cole CJ, Matynia A, Brown RA, Neve RL, Guzowski JF, Silva AJ, Josselyn SA (2007) Neuronal competition and selection during memory formation. Science 316:457-460. CrossRef Medline

Han JH, Kushner SA, Yiu AP, Hsiang HL, Buch T, Waisman A, Bontempi B, Neve RL, Frankland PW, Josselyn SA (2009) Selective erasure of a fear memory. Science 323:1492-1496. CrossRef Medline

Hashikawa K, Matsuki N, Nomura H (2011) Preferential Arc transcription at rest in the active ensemble during associative learning. Neurobiol Learn Mem 95:498-504. CrossRef Medline

Johansen JP, Hamanaka H, Monfils MH, Behnia R, Deisseroth K, Blair HT, LeDoux JE (2010) Optical activation of lateral amygdala pyramidal cells instructs associative fear learning. Proc Natl Acad Sci U S A 107:1269212697. CrossRef Medline

Josselyn SA, Kida S, Silva AJ (2004) Inducible repression of CREB function disrupts amygdala-dependent memory. Neurobiol Learn Mem 82:159163. CrossRef Medline

Kim MJ, Mizumori SJ, Bernstein IL (2010) Neuronal representation of con- 
ditioned taste in the basolateral amygdala of rats. Neurobiol Learn Mem 93:406-414. CrossRef Medline

Koh MT, Thiele TE, Bernstein IL (2002) Inhibition of protein kinase A activity interferes with long-term, but not short-term, memory of conditioned taste aversions. Behav Neurosci 116:1070-1074. CrossRef Medline

Lim F, Neve RL (2001) Generation of high-titer defective HSV-1 vectors. Curr Protoc Neurosci Chapter 4:Unit4.13.

Miranda MI, Ferreira G, Ramirez-Lugo L, Bermudez-Rattoni F (2002) Glutamatergic activity in the amygdala signals visceral input during taste memory formation. Proc Natl Acad Sci U S A 99:11417-11422. CrossRef Medline

Miura Y, Naka M, Matsuki N, Nomura H (2012) Differential calcium dependence in basal and forskolin-potentiated spontaneous transmitter release in basolateral amygdala neurons. Neurosci Lett 529:1-6.

Paxinos G, Franklin KBJ (2001) The mouse brain in stereotaxic coordinates, Ed 2. San Francisco: Academic.

Reilly S, Bornovalova MA (2005) Conditioned taste aversion and amygdala lesions in the rat: a critical review. Neurosci Biobehav Rev 29:1067-1088. CrossRef Medline

Rogan MT, Stäubli UV, LeDoux JE (1997) Fear conditioning induces asso- ciative long-term potentiation in the amygdala. Nature 390:604-607. CrossRef Medline

Sakaguchi M, Hayashi Y (2012) Catching the engram: strategies to examine the memory trace. Mol Brain 5:32. CrossRef Medline

Samson RD, Paré D (2006) A spatially structured network of inhibitory and excitatory connections directs impulse traffic within the lateral amygdala. Neuroscience 141:1599-1609. CrossRef Medline

Tan EM, Yamaguchi Y, Horwitz GD, Gosgnach S, Lein ES, Goulding M, Albright TD, Callaway EM (2006) Selective and quickly reversible inactivation of mammalian neurons in vivo using the Drosophila allatostatin receptor. Neuron 51:157-170. CrossRef Medline

Yasoshima Y, Morimoto T, Yamamoto T (2000) Different disruptive effects on the acquisition and expression of conditioned taste aversion by blockades of amygdalar ionotropic and metabotropic glutamatergic receptor subtypes in rats. Brain Res 869:15-24. CrossRef Medline

Zhou Y, Won J, Karlsson MG, Zhou M, Rogerson T, Balaji J, Neve R, Poirazi P, Silva AJ (2009) CREB regulates excitability and the allocation of memory to subsets of neurons in the amygdala. Nat Neurosci 12:1438-1443. CrossRef Medline 